-

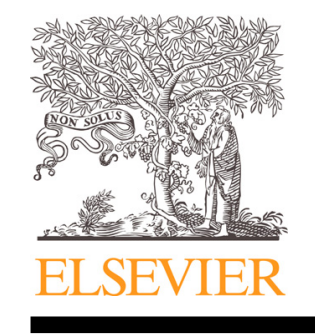

\section{What is optimal wound management to prevent infection in non-hand mammalian bite Injuries? A systematic review}

\section{Dear Sir,}

Mammalian bites account for 1\% of all Emergency Department (ED) visits in the United Kingdom, with infection rates varying from $2 \%$ to $20 \%$. $^{1,2}$ Mammalian bites on the hand, where tendons and joints are more superficial, are more prone to infection and should be considered separately.

There is no consensus on how to prevent infection in mammalian bite wounds. ${ }^{3}$ Primary closure of the bite wound has received considerable attention and was initially argued to increase infection rates, ${ }^{1}$ although others suggest rates are reduced. ${ }^{4}$ Management of the initial wound is likely to be a significant factor. Prophylactic antibiotics have limited benefit, and wound management is variable and may comprise: (1) wound cleansing or (2) irrigation, with or without debridement. ${ }^{3}$ Some authors advocate early surgical inpatient treatment to prevent infection, ${ }^{5}$ while others perform irrigation with or without debridement in the ED. ${ }^{6}$

The aim of this systematic review is to determine optimal wound management to reduce the risk of infection in nonhand, mammalian bite wounds.

\section{Methods}

Three authors (JAD, AK and RJC) independently carried out a systematic literature review of all studies in Ovid MEDLINE, Ovid EMBASE and the Cochrane Central Register of Controlled trials. Both 'free-text term' and 'MeSH term' searches were performed using the search terms (Boolean operators italicised): [mammal* OR dog* OR fight* OR human* OR cat* OR animal*] AND [bit*] AND [wound*], restricted to English language.

All papers reporting wound management for mammalian bites and infection rates were included. Papers reporting on penetration of internal viscera, eyes, and hand and wrist bites were excluded, as were those with no comparison group, as studies are disparate in terms of animal bite, location, time to presentation and wound care, preventing comparison. Papers outlining method of closure with no reference to wound management were also discarded.
The search was last undertaken in November 2018. The study selection process was performed in accordance with the PRISMA statement (Figure 1). 2095 studies were identified, with 154 retrieved for detailed review. 147 did not meet inclusion criteria and five were excluded. Two papers were included in the review. The primary outcome measure was incidence of infection.

\section{Results}

Two studies were included and both were case series (Table 1). ${ }^{6,7}$ The first included 106 patients all treated in $E D$, managed by one or more of the following; irrigation, debridement and antibiotics. Twelve percent of irrigated wounds developed infection, compared to $69 \%$ without irrigation. Debridement was performed in 14 cases but not performed in 46 , and infection rates were $7 \%$ and $17 \%$, respectively.

The second study included 704 cases. A total of 159 wounds contaminated with dirt, blood or devitalised tissue were scrubbed first with a povidone-iodine sponge, and four became infected (2.5\%), compared to 606 wounds not scrubbed prior to irrigation, with 12 becoming infected (2.0\%). Thirteen patients had devitalised tissue which was excised, with 13\% developing infection, compared to 742 who were not debrided, and $1.8 \%$ developing infection.

Both studies were observational in design and were therefore at high risk of bias through methodological limitations, according to comprehensive risk of bias assessment with the Cochrane Risk of Bias Tool. ${ }^{8}$

\section{Discussion}

Mammalian bite wounds carry significant costs to health services, estimated to be US\$160 million per year in the United States. ${ }^{9}$ In spite of their huge burden, best treatment to prevent development of infection remains unknown following this systematic review. The two studies conflicted in terms of outcome for debridement, and had individual suggestions for optimal management, with irrigation proposed to reduce infection.

The two series in this review are limited by their observational design to account for confounding factors. Callaham's study was a retrospective review, and may be prone to recall bias. It is not possible to ascertain what constituted debridement, and hence there may be significant heterogeneity in the intervention patients received. 


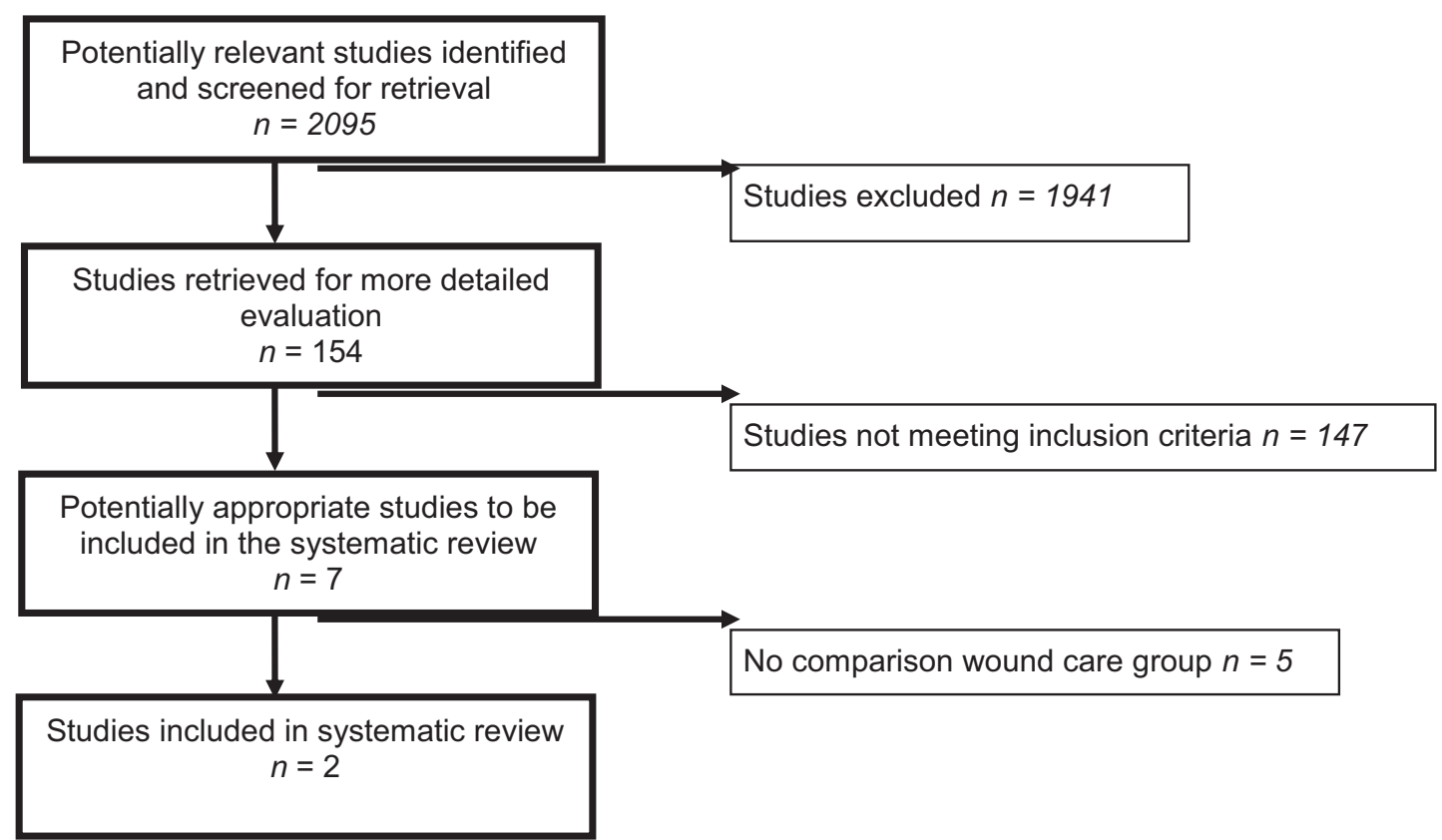

Figure 1 PRISMA flow diagram demonstrating the search strategy for the review.

\begin{tabular}{|c|c|c|c|c|c|c|c|}
\hline Author & Country & Design & $\begin{array}{l}\text { Mammal } \\
\text { bite }\end{array}$ & Patients & Intervention & Comparison & Primary outcome \\
\hline \multirow[t]{2}{*}{ Callaham $^{7}$} & USA & $\begin{array}{l}\text { Retrospective } \\
\text { series }\end{array}$ & Dog & 106 & $\begin{array}{l}\text { Irrigated with } \\
\quad>150 \mathrm{ml} \text { normal } \\
\text { saline through } 19 \mathrm{G} \\
\text { needle }(n=44)\end{array}$ & $\begin{array}{l}\text { Not irrigated } \\
\quad(n=1)\end{array}$ & $\begin{array}{l}13.6 \% \text { of irrigated } \\
\text { wounds infected } \\
\text { compared to } 0 \% \text { not } \\
\text { irrigated }\end{array}$ \\
\hline & & & & & $\begin{array}{l}\text { Debrided by excision } \\
\text { of devitalised } \\
\text { tissue }(n=14)\end{array}$ & $\begin{array}{l}\text { Not debrided } \\
\quad(n=46)\end{array}$ & $\begin{array}{l}\text { 7.1\% of debrided became } \\
\text { infected vs } 17 \% \text { not } \\
\text { debrided } P \text { value }\end{array}$ \\
\hline \multirow[t]{2}{*}{ Dire et al. ${ }^{6}$} & USA & $\begin{array}{l}\text { Prospective } \\
\text { series }\end{array}$ & Dog & 704 & $\begin{array}{l}\text { Providone-iodine- } \\
\text { impregnated } \\
\text { sponge to scrub } \\
\text { prior to irrigation } \\
(n=159)\end{array}$ & $\begin{array}{l}\text { No scrub prior } \\
\text { to irrigation } \\
(n=606)\end{array}$ & $\begin{array}{l}4(2.5 \%) \text { with scrubbing } \\
\text { developed infection vs } \\
12(2.0 \%) \text { who were } \\
\text { not scrubbed } \\
(P=0.76)\end{array}$ \\
\hline & & & & & $\begin{array}{l}\text { Excision devitalised } \\
\text { tissue }(n=23 \\
\text { wounds })\end{array}$ & $\begin{array}{l}\text { No excision } \\
\text { ( } n=742 \\
\text { wounds) }\end{array}$ & $\begin{array}{l}\text { 13.0\% with excision } \\
\text { devitalised tissue } \\
\text { developed infection vs } \\
1.8 \% \text { who did not } \\
(P=0.01)\end{array}$ \\
\hline
\end{tabular}

Admission rates for patients presenting with mammalian bites ranges from $5 \%$ to $51 \%,{ }^{10}$ and factors associated with admission include underlying structural injury on clinical assessment, large or multiple wounds, and bites where children require general anaesthesia. It is currently unclear whether all other wounds could be managed in ED.

Wounds considered to be higher risk for infection include those presenting more than 24 hours after a bite causing puncture wounds, having almost double the infection rate compared to bites causing lacerations. This may be due to a crush, which can devitalise tissues and harbour infection. ${ }^{10}$ The higher infection rate may be due to difficulty irrigating the wound or debriding deep, devitalised tissue. Whether these wounds can be managed under local anaesthesia in ED is unclear, because of non-standardised treatment between centres.

Mammalian bite injuries are a common problem without clear evidence to define best practice. Further evidence is required which should have a significant clinical, organisational and financial impact.

\section{Conflicts of interest}

None 


\section{Funding}

None

\section{References}

1. Goldstein EJ. Bite wounds and infection. Clin Infect Dis 1992;14:633-40.

2. Callaham M. Controversies in antibiotic choices for bite wounds. Ann Emerg Med 1988;17:1321-9.

3. Smith M, Walker A, Brenchley J. Barking up the wrong tree? A survey of dog bite wound management. Emerg Med J 2003;20:253-5.

4. Zook EG, Miller M, Van Beek AL, Wavak P. Successful treatment protocol for canine fang injuries. J Trauma Acute Care Surg 1980;20:243-7.

5. Akhtar N, Smith M, McKirdy S, Page R. Surgical delay in the management of dog bite injuries in children, does it increase the risk of infection? J Plast Reconstr Aesthet Surg 2006; 59:80-5.

6. Dire DJ, Hogan DE, Riggs MW. A prospective evaluation of risk factors for infections from dog-bite wounds. Acad Emerg Med 1994; 1:258-66.

7. Callaham ML. Treatment of common dog bites: infection risk factors. JACEP 1978;7:83-7.

8. Higgins JP, Altman DG, Gøtzsche PC, et al. The Cochrane Collaboration's tool for assessing risk of bias in randomised trials. Br Med J 2011;343:d5928.

9. Weiss HB, Friedman DI, Coben JH. Incidence of dog bite injuries treated in emergency departments. JAMA 1998;279:51-3.

10. Chiam SC, Solanki NS, Lodge M, Higgins M, Sparnon AL. Retrospective review of dog bite injuries in children presenting to a South Australian tertiary children's hospital emergency department. J Paediatr Child Health 2014;50:791-4.

Jonathan A Dunne

Department of Plastic and Reconstructive Surgery, Charing Cross Hospital, Fulham Palace Rd, Hammersmith, London W6 8RF, United Kingdom

E-mail address: jonathan.dunne1@nhs.net
Aadil Khan

Department of Plastic and Reconstructive Surgery, John Hopkins Hospital, 1800 Orleans Street, Baltimore, MD, United States of America

Justin CR Wormald Department of Plastic and Reconstructive Surgery, Stoke Mandeville Hospital, Mandeville Rd, Aylesbury HP21 8AL,

United Kingdom

Nuffield Department of Orthopaedics, Rheumatology and Musculoskeletal Sciences, University of Oxford, Roosevelt Drive, Oxford OX3 7FY, United Kingdom

Abhilash Jain

Nuffield Department of Orthopaedics, Rheumatology and Musculoskeletal Sciences, University of Oxford, Roosevelt Drive, Oxford OX3 7FY, United Kingdom Department of Plastic and Reconstructive Surgery, Imperial College Healthcare NHS Trust, St Mary's Hospital, Praed St, London W2 1NY, United Kingdom

R James Colville

Department of Plastic and Reconstructive Surgery, St George's Hospital, Blackshaw Road, London SW17 OQT, United Kingdom

Correspondence to: Jonathan A Dunne, Department of Plastic and Reconstructive Surgery, Charing Cross Hospital, Fulham Palace Rd, Hammersmith, London W6 8RF, United Kingdom. (C) 2019 British Association of Plastic, Reconstructive and Aesthetic Surgeons. Published by Elsevier Ltd. All rights reserved.

https://doi.org/10.1016/j.bjps.2019.01.019 